Short Communication

\title{
The diamide insecticide chlorantraniliprole increases the single-channel current activity of the mammalian skeletal muscle ryanodine receptor
}

\author{
Zsuzsanna É. Magyar ${ }^{1}$, Gyula Diszházi ${ }^{1}$, Judit Péli-Szabó ${ }^{2}$, Péter Szentesi ${ }^{1}$, Claude Collet ${ }^{3}$, \\ László Csernoch ${ }^{1}$, Péter Nánási ${ }^{1}$ and János Almássy ${ }^{1}$ \\ ${ }^{1}$ Department of Physiology, Faculty of Medicine, University of Debrecen, Debrecen, Hungary \\ ${ }^{2}$ Medical Imaging Department, Division of Nuclear Medicine, Faculty of Medicine, University of Debrecen, Debrecen, Hungary \\ ${ }^{3}$ INRA, UR 406 Abeilles et Environnement, Toxicologie Environnementale, Avignon, France, UMT Protection des Abeilles \\ dans l'Environnement, Avignon, France
}

\begin{abstract}
Very recently, the diamide insecticide chlorantraniliprole was shown to induce $\mathrm{Ca}^{2+}$-release from sarcoplasmic reticulum (SR) vesicles isolated from mammalian skeletal muscle through the activation of the $\mathrm{SR} \mathrm{Ca}^{2+}$ channel ryanodine receptor. As this result raises severe concerns about the safety of this chemical, we aimed to learn more about its action. To this end, single-channel analysis was performed, which showed that chlorantraniliprole induced high-activity bursts of channel opening that accounts for the $\mathrm{Ca}^{2+}$-releasing action described before.
\end{abstract}

Key words: Ryanodine receptor — Diamide — Insecticide - Chlorantraniliprole

Abbreviations: CP, chlorantraniliprole; MHS, malignant hyperthermia susceptibility; $\mathrm{P}_{\mathrm{O}}$, open probability; RyR, ryanodine receptor.

Diamide insecticides kill Lepidoptera by inducing muscle paralysis. They act by triggering $\mathrm{Ca}^{2+}$-release from the endoplasmic reticulum through the activation of ryanodine receptor $\mathrm{Ca}^{2+}$-release ion channels (RyR). Although, diamides were shown to be relatively selective to activate insect RyR comparing to mammalian RyRs (approximately by two orders of magnitude) (Sattelle et al. 2008), a recent study by Truong and Pessah raises severe food safety concerns with this class of insecticides. The authors argue that there are certain point mutations in the RyR gene, rendering the channel oversensitive to its agonists. These mutations are typically linked to malignant hyperthermia susceptibility (MHS). In these patients, therapeutic (normally sub-threshold) concentrations of volatile anesthetics (e.g. halothane, isoflurane, enflurane) trigger uncontrolled $\mathrm{Ca}^{2+}$-release, leading to muscle contractures, hyperthermia and death (Rosenberg et al. 2007; Truong and Pessah 2018), unless appropriate and immediate medical

Correspondence to: János Almássy, Department of Physiology, Faculty of Medicine, University of Debrecen, PO Box: 400, Debrecen 4002, Hungary

E-mail: almassy.janos@med.unideb.hu treatment is given. This includes body-cooling and administration of the RyR inhibitor dantrolene (Riazi et al. 2018).

Truong and Pessah reported that the diamide insecticide chlorantraniliprole (CP, chemical structure is shown in Figure 1) evoked robust $\mathrm{Ca}^{2+}$-release from mammalian sarcoplasmic reticulum (SR) microsomes, and more importantly, that RyRs from MHS mice were extremely sensitive to $\mathrm{CP}$ activation. As there are documented cases when $\mathrm{MH}$ episodes were triggered by heat stress (Roux-Buisson et al. 2016), they also investigated whether diamide treatment exacerbated heat stress intolerance in MHS-RyR knockin mice. Although, CP treatment did not shift the onset temperature of $\mathrm{MH}$ crisis toward lower temperatures, these results do not rule out the possibility that $\mathrm{CP}$ could act as an $\mathrm{MH}$-trigger agent in some MHS individuals, since a wide variety (above 400) of MHS mutations have been identified to date (Truong and Pessah 2018).

Unfortunately, little information is available about the CP binding site, however competitive binding assays showed that it is distinct from the binding site of ryanodine (the natural ligand, originally used as a natural insecticide) (Sattelle et al. 2008; Isaacs et al. 2012). Recently, molecular 
<smiles>CNC(=O)c1cc(Cl)cc(C)c1NC(=O)c1cc(Br)nn1-c1ncccc1Cl</smiles>

Figure 1. Chemical structure of chlorantraniliprole.

docking of various CP-derivatives on moths RyR predicted the binding site to be located in the membrane-spanning region the protein (Luo et al. 2014) (which is considered to be one of the most evolutionally conserved domains), indicating that $\mathrm{CP}$ promotes the channel's gating by increasing the mobility of the transmembrane helices.

Nevertheless, since diamides may have relevant toxicological importance, we should learn more about the molecular mechanism of the action of these compounds. As single channel analysis is essential to our understanding, in the present paper we wish to add this important data to Truong and Pessah`s research. To this end, we purified
RyRs from rabbit skeletal muscle (RyR1) as described earlier. Briefly, skeletal muscle from a rabbit was homogenized and SR microsome fraction was separated by differential centrifugation. Thereafter, RyR1 channels were solubilized with the detergent CHAPS and purified by centrifugation on a $10-28 \%$ linear sucrose gradient overnight. The RyRcontaining fraction was identified and aliquoted. RyR1 from these samples were incorporated into planar lipid bilayers and single channel currents were recorded under voltageclamp condition (Sárközi et al. 2017). The lipid mixture contained phosphatidylethanolamine, phosphatidylserine and phosphatidylcholine (Avanti Polar Lipids, Alabaster, $\mathrm{AL}$ ) in a ratio of 5:4:1 dissolved in $n$-decane in the final lipid concentration of $20 \mathrm{mg} / \mathrm{ml}$.

In Figure 2, such a single-channel current record is shown under control conditions (in $96 \mathrm{nM}$ cytoplasmic $\mathrm{Ca}^{2+}$ ) and in the presence of 3 or $10 \mu \mathrm{M} \mathrm{CP}$. These 2.5-5-minute-long recordings show that highly active bursts of currents (labelled with asterisks) appeared in the presence of $\mathrm{CP}$, with higher frequency at higher concentration CP (events were regarded as "bursts" when the open probability of the channel suddenly increased $>10$ fold of normal activity and lasted longer than $200 \mathrm{~ms}$ ). This effect is qualitatively different from the effect of ryanodine, which locks the channel in a characteristic half-open state.

control

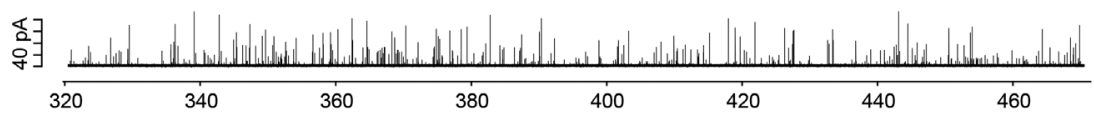

$3 \mu \mathrm{M} \mathrm{CP}$
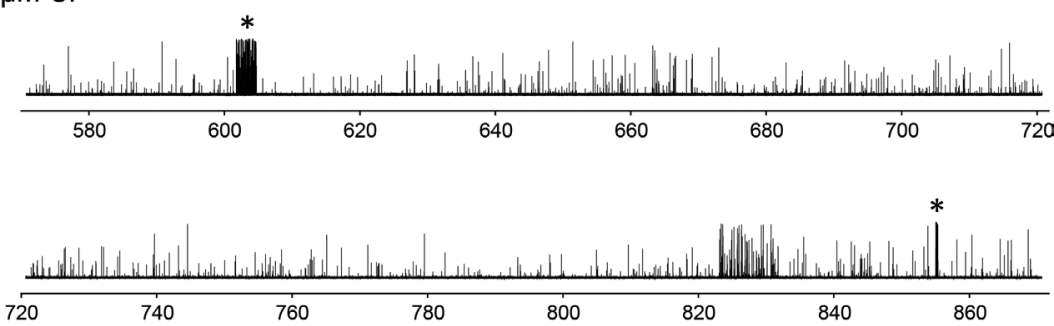

$10 \mu \mathrm{M} \mathrm{CP}$
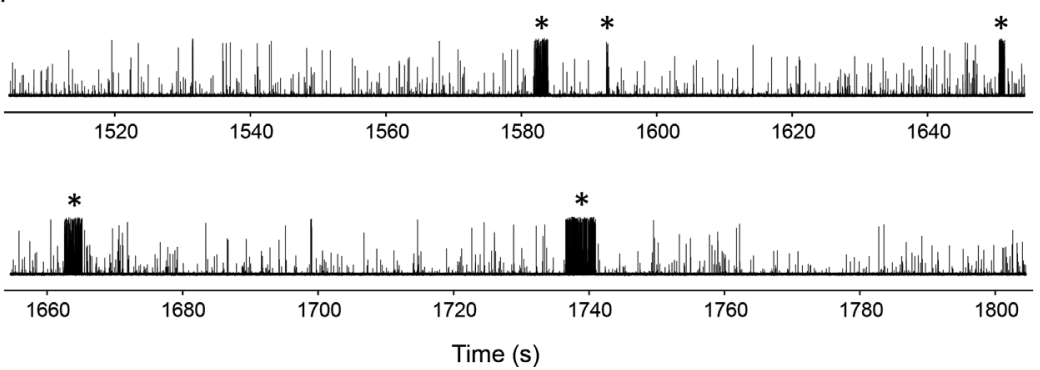

Figure 2. Chlorantraniliprole (CP) induces high-activity bursts of RyR1 activity. 2.5-minutes long current traces of a single ryanodine receptor channel. Upward deflections correspond to single openings of the channel. Bursts of active periods are labelled with asterisks. 
Table 1. Evaluation of channel behavior under chlorantraniliprole (CP) treatment

\begin{tabular}{lccc}
\hline & control & $3 \mu \mathrm{M} \mathrm{CP}$ & $10 \mu \mathrm{M} \mathrm{CP}$ \\
\hline inter burst $\mathrm{P}_{\mathrm{o}}$ & $0.00617 \pm 0.00298$ & $0.02762 \pm 0.02344$ & $0.02502 \pm 0.01831$ \\
burst $\mathrm{P}_{\mathrm{o}}$ & $\mathrm{N} / \mathrm{A}$ & $0.2019 \pm 0.0837$ & $0.3651 \pm 0.1637$ \\
mean burst duration $(\mathrm{s})$ & $\mathrm{N} / \mathrm{A}$ & $3.93 \pm 2.76$ & $1.66 \pm 0.38$ \\
burst frequency $(1 / \mathrm{min})$ & $\mathrm{N} / \mathrm{A}$ & $0.77 \pm 0.43$ & $1.74 \pm 0.56$ \\
\hline
\end{tabular}

$\mathrm{N} / \mathrm{A}$, not available; $\mathrm{P}_{\mathrm{O}}$, open probability.

In order to take a closer look at the current records, a shorter period of a current record is shown on an expanded time scale in Figure 3A. First, the current was recorded in the presence of $50 \mu \mathrm{M} \mathrm{Ca}^{2+}$, allowing the estimation of maximal open probability $\left(\mathrm{P}_{\mathrm{o}}=0.63\right)$. Thereafter, $\left[\mathrm{Ca}^{2+}\right]$ was lowered on the cytoplasmic side of the channel close to the resting $\left[\mathrm{Ca}^{2+}\right]$ of muscle fibers $(96 \mathrm{nM})$. Accordingly, $\mathrm{P}_{\mathrm{o}}$ decreased significantly to 0.00028 , as the channel barely opened. This behavior indicates the physiological integrity of the protein. Treating the same RyR with $3 \mu \mathrm{M} \mathrm{CP}$ increased $\mathrm{P}_{\mathrm{o}}$ to 0.00036 . Raising $\mathrm{CP}$ concentration to $10 \mu \mathrm{M}$ further activated the channel resulting in a $\mathrm{P}_{\mathrm{o}}$ value of 0.00276 . This $\mathrm{P}_{\mathrm{o}}$-analysis was performed by using at least 2-minute-long continuous current records, where burst and inter-burst activities were not distinguished. $\mathrm{P}_{\mathrm{o}}$ values of three $\mathrm{CP}$-treated RyRs were normalized to control values of the same RyR and expressed as mean \pm SEM in Figure 3B. Apparently, this increase in $P_{o}$ can mostly be attributed to the appearance of high- $\mathrm{P}_{\mathrm{o}}$ bursts (marked by asterisks in the third and the forth traces). The results of the quantitative analysis of bursts are summarized in Table 1. Note that we have never observed burst-like behavior in the absence of $\mathrm{CP}$. The frequency of bursts was markedly higher in $10 \mu \mathrm{M} \mathrm{CP}$ as compared to $3 \mu \mathrm{M}$, while the inter-burst $\mathrm{P}_{\mathrm{o}}$ of all the investigated channels slightly increased. These data suggest that $\mathrm{CP}$ binds to the open state of the channel, which is a quite unique mode of action. It is also noteworthy that these data are in accordance with Truong and Pessah's results showing that the action of $\mathrm{CP}$ was $\mathrm{Ca}^{2+}$-dependent.

Although, Truong and Pessah did not observe any obvious acute cardiotoxic effects of diamides in healthy mice, one documented case of deliberate self-harm abuse attracts attention to the cardiologic safety hazard of CP (Mishra et al. 2016). As the otherwise healthy patient developed Mobitz Type I atrioventricular block (which may indicate the involvement of RyR2 in the toxicological process), the question whether diamides actually affect the cardiac isoform of RyR (RyR2) is a critical question to be answered. This question is especially important since the open channel binding preference of $\mathrm{CP}$ may be a particularly worrisome feature of the poison under certain arrhythmogenic conditions, associated with high diastolic activity of the RyR2 (e.g. catecholaminergic ventricular tachycardia (CPVT) or chronic heart failure; Betzenhauser and Marks 2010). Future experiments are re-

\section{A}

control $\left(50 \mu \mathrm{M} \mathrm{Ca}^{2+}\right)$
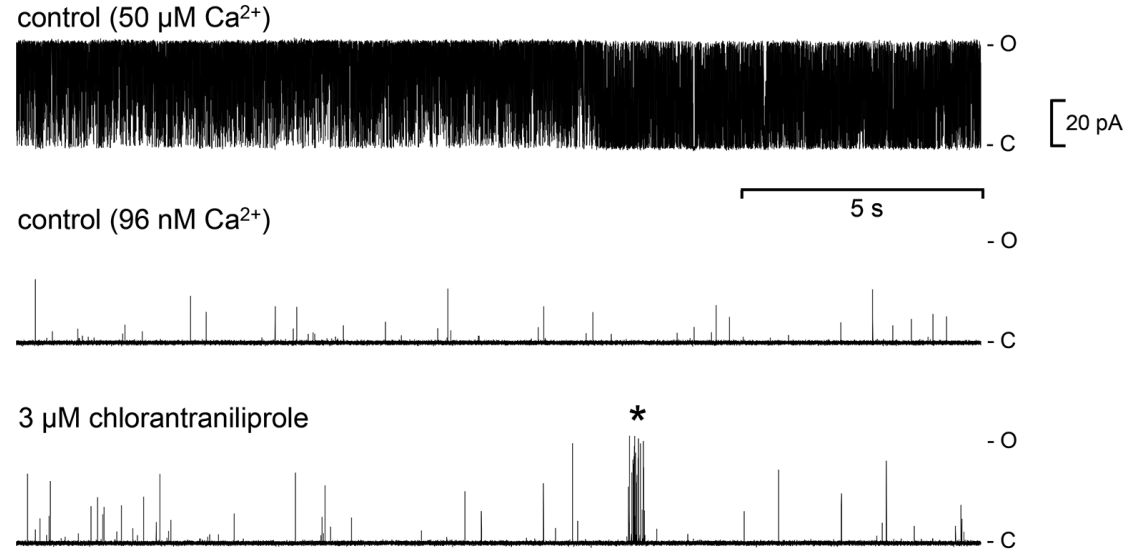

$10 \mu \mathrm{M}$ chlorantraniliprole *

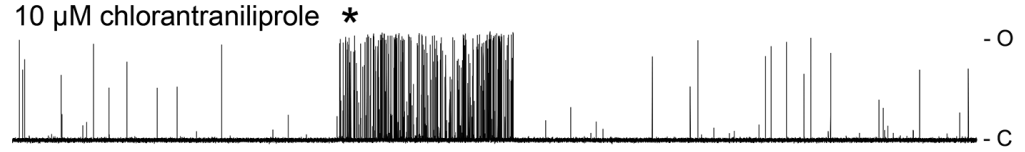

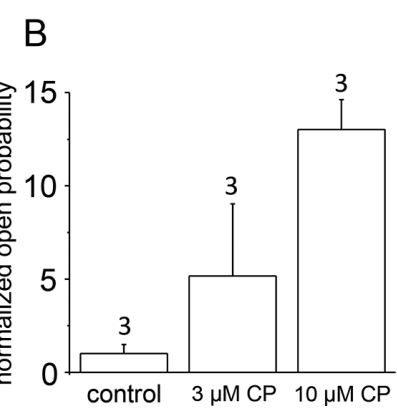

Figure 3. Chlorantraniliprole (CP) increases the open probability of the RyR. A. Current traces of a single RyR channel under control conditions and in the presence of chlorantraniliprole. "C" and "O" indicates closed and open states, respectively. B. Normalized and averaged open probabilities of 3 single channels. 
quired to answer the question whether RyR2 is sensitive to $\mathrm{CP}$ under pathological conditions. Until that extra care has to be taken with widespread application of this type of insecticides.

Acknowledgements. This work was supported by grants from the Hungarian National Research, Development and Innovation Office (NKFIH: K-115461, K115397 and GINOP-2.3.2-15-2016-00040). The project is co-financed by the European Union and the European Regional Development Fund. JA is supported by the Lajos Szodoray Scholarship of the University of Debrecen." GD was supported by the ÚNKP-18-3 NEW NATIONAL EXCELLENCE PROGRAM of the Ministry of Human Capacities."

\section{References}

Betzenhauser MJ, Marks AR (2010): Ryanodine receptor channelopathies. Pflugers. Arch. 460, 467-480

https://doi.org/10.1007/s00424-010-0794-4

Isaacs AK, Qi S, Sarpong R, Casida JE (2012): Insect ryanodine receptor: distinct but coupled insecticide binding sites for $[\mathrm{N}-\mathrm{C}(3) \mathrm{H}(3)]$ chlorantraniliprole, flubendiamide, and $[(3) \mathrm{H}]$ ryanodine. Chem. Res. Toxicol. 25, 1571-1573 https://doi.org/10.1021/tx300326m

Luo M, Chen Q, Wang J, Hu C, Lu J, Luo X, Sun D (2014): Novel chlorantraniliprole derivatives as potential insecticides and probe to chlorantraniliprole binding site on ryanodine receptor. Bioorg. Med. Chem. Lett. 24, 1987-1992 https://doi.org/10.1016/j.bmcl.2014.02.053

Mishra AK, Chandiraseharan VK, Jose N, Sudarsanam TD (2016): Chlorantraniliprole: An unusual insecticide poisoning in humans. Indian J. Crit. Care Med. 20, 742-744 https://doi.org/10.4103/0972-5229.195718

Riazi S, Kraeva N, Hopkins PM (2018) Updated guide for the management of malignant hyperthermia. Can. J. Anaesth. 65, 709-721

https://doi.org/10.1007/s12630-018-1108-0

Rosenberg H, Davis M, James D, Pollock N, Stowell K (2007): Malignant hyperthermia. Orphanet J. Rare Dis. 2, 21 https://doi.org/10.1186/1750-1172-2-21

Roux-Buisson N, Monnier N, Sagui E, Abriat A, Brosset C, Bendahan D, Kozak-Ribbens G, Gazzola S, Quesada JL, Foutrier-Morello C, et al. (2016): Identification of variants of the ryanodine receptor type 1 in patients with exertional heat stroke and positive response to the malignant hyperthermia in vitro contracture test. Br. J. Anaesth. 116, 566-568 https://doi.org/10.1093/bja/aew047

Sárközi S, Komáromi I, Jóna I, Almássy J (2017): Lanthanides report calcium sensor in the vestibule of ryanodine receptor. Biophys. J. 112, 2127-2137 https://doi.org/10.1016/j.bpj.2017.03.023

Sattelle DB, Cordova D, Cheek TR (2008): Insect ryanodine receptors: molecular targets for novel pest control chemicals. Invert Neurosci. 8, 107-119 https://doi.org/10.1007/s10158-008-0076-4

Truong KM, Pessah IN (2019): Comparison of chlorantraniliprole and flubendiamide activity towards wild type and malignant hyperthermia-susceptible ryanodine receptors and heat stress intolerance. Toxicol. Sci. 167, 509-523 https://doi.org/10.1093/toxsci/kfy256

Received: January 3, 2019

Final version accepted: February 15, 2019

First published online: March 1, 2019 


\title{
Short Communication
}

\section{Chronic predator scent stress alters serotonin and dopamine levels in the rat thalamus and hypothalamus, respectively}

\author{
Eliyahu Dremencov ${ }^{1,2,3}$, Maxim Lapshin ${ }^{3}$, Maria Komelkova ${ }^{3}$, Anatoli Alliluev³, Olga \\ Tseilikman ${ }^{3}$, Marina Karpenko ${ }^{4}$, Nina Pestereva ${ }^{4}$, Eugenia Manukhina ${ }^{5,6}$, H. Fred \\ Downey $^{6}$ and Vadim Tseilikman ${ }^{3}$ \\ ${ }^{1}$ Institute of Molecular Physiology and Genetics, Centre for Biosciences, Slovak Academy of Sciences, Bratislava, Slovakia \\ ${ }^{2}$ Institute of Experimental Endocrinology, Biomedical Research Center, Slovak Academy of Sciences, Bratislava, Slovakia \\ ${ }^{3}$ School of Medical Biology, South Ural State University, Chelyabinsk, Russia \\ ${ }^{4}$ Institute of Experimental Medicine, Saint Petersburg, Russia \\ ${ }^{5}$ Institute of General Pathology and Pathophysiology, Moscow, Russia \\ ${ }^{6}$ University of North Texas Health Science Center, Fort Worth, TX, USA
}

\begin{abstract}
The aim of this study was to investigate the effect of chronic predator scent stress (PSS) on monoamine levels in rat thalamus and hypothalamus. Rats were exposed to the PSS (sand containing cat urine) for ten minutes daily for ten days. Control animals were exposed to the sand containing clean water. Fifteen days later, rats' behavior and thalamic and hypothalamic levels of monoamines were analyzed. PSS rats had elevated anxiety, increased thalamic serotonin and decreased hypothalamic dopamine concentrations. This decrease in hypothalamic dopamine may explain, at least in part, lowered corticosterone levels observed in PSS animals in our previous studies.
\end{abstract}

Key words: Post-traumatic stress disorder - Predator scent stress - Serotonin — Norepinephrine - Dopamine - HPLC

Repeated exposure of the rats to the predator scent stress (PSS) has been used in our previous studies as an animal model of post-traumatic stress disorder (PTSD). We had previously reported that repeated PSS induce long-lasting behavioral changes, such as increased anxiety index (AI), observed as late as fourteen days after the last PSS exposure (Lazuko et al. 2018; Manukhina et al. 2018). Repeated PSS might be a more accurate model for PTSD than the acute one, since it minimizes the effect of uncontrolled factors, such as concentration of pheromones in each individual dose of urine. Indeed, rats repeatedly exposed to the PSS have showed some abnormalities which were not observed after the acute exposure, such as decreased plasma corticosterone levels and adrenal hypotrophy (Manukhina et al. 2018).

Correspondence to: Vadim E. Tseilikman, School of Medical Biology, South Ural State University, 76 Lenin Ave, Chelyabinsk, Russia 454080

E-mail: vadimed@yandex.ru
Monoamine (serotonin or 5-HT, norepinephrine, and dopamine) systems of the brain are fundamental in the memory, cognition, and emotions (Stahl et al. 2014), the functions which are impaired in PTSD (American Psychiatric Association. DSM-5 Task Force. 2013). Indeed, monoamine abnormalities in PTSD were reported (Feduccia and Mithoefer 2018).

Majority of studies on neurophysiology and neurochemistry of PTSD are focusing in prefrontal cortex, hippocampus, amygdala, nucleus accumbens, and related limbic brain areas. The research on these brain areas has provided highly relevant information on the etiology of PTSD. However, the role of other brain areas, such as thalamus and hypothalamus, remained relatively under-investigated. Thalamus is a hub for all sensory information entering the brain. Certain thalamic nuclei, such as paraventricular nucleus, regulates emotional response to the sensory stimuli (Hsu et al. 2014). Since the inadequate emotional response to the certain sensory stimuli is a key feature of PTSD, thalamus might play a role in pathophysiology of this disorder. Indeed, 
recent studies showed that thalamic neural circuits are involved in the response to the threatening sensory stimuli (Dunkley et al. 2018) and in the fear extinction (Silva et al. 2018) in PTSD.

Hypothalamus is fundamental in the central regulation of endocrine functions, including the stress hormone signaling. Altered functioning of the hypothalamic-pituitary-adrenal axis was detected in patients with PTSD (Cooper et al. 2017) and in an animal model of this disorder (Boero et al. 2018). Finally, thalamic-hypothalamic interconnections are important in the choosing of the coping strategy to the predatory threats in rodents (Cezario et al. 2008). In this study, we aimed to investigate the role of thalamic and hypothalamic monoamine transmission in PTSD, using our animal model of this illness.

Adult male Wistar rats were used in all experiments. Rats were housed in standard cages (4-5 animals/cage) and received food and water ad libitum. The animals were maintained at controlled temperature $\left(22-25^{\circ} \mathrm{C}\right)$ and humidity (55\%). A 12:12 h light-dark cycle was maintained with lights on between 7:00 and 19:00. All animal procedures were performed in accordance with the U.S. National Research Council Guide for the Care and Use of Laboratory Animals (publication 85-23, revised 2011), and experimental protocols were approved by the Animal Care and Use Committee of the Institute of General Pathology and Pathophysiology, Moscow, Russia.

The rats were randomly divided to two groups: control $(n=7)$ and PSS $(n=9)$. The sand containing fresh cat urine was collected daily from the litterbox of a domestic cat. This sand was stored at the room temperature in the closed plastic container for 3-5 h before the experiment. Twenty gram of this sand was laid in a Petri dish covered with nylon tissue and placed in the home cage of PSS rats for 15 min daily, between 13:00 and 14:00, during 10 consecutive days. Control rats were exposed to the sand containing clean water. Control and PSS rats were kept in different rooms with separate air conditioning systems. After the last exposure, the rats were left intake for 15 days. On the $15^{\text {th }}$ day after the last exposure, the rats' level of anxiety was measured using the elevated plus maze (EPM) test, as previously described Lazuko et al. (2018), Manukhina et al. (2018). The AI was calculated using the formula: $\mathrm{AI}=1-[$ (time in open arms/total time on maze $)+$ (number of entries into open arms/number of all entries)]/2.
Twenty-four hours after the EPM test the rats were decapitated and their brains were removed. The whole left and right thalami (7-10 $\mathrm{mm}$ posterior from the frontal pole, $3-6 \mathrm{~mm}$ dorsal from the ventral brain surface, and 0-3 mm lateral from the midline) and hypothalami $(7-10 \mathrm{~mm}$ posterior from the frontal pole, $0-3 \mathrm{~mm}$ dorsal from the ventral brain surface, and 0-2 mm lateral from the midline; Paxinos and Watson 2014) were isolated and frozen in liquid nitrogen for the subsequent neurochemical assessments, which were performed within seven days after the tissue collection. For the quantification of monoamines, brain tissue was homogenized in $0.1 \mathrm{M}$ perchloric acid. After homogenization the samples were centrifuged $\left(7000 \times g\right.$ for $15 \mathrm{~min}$ at $\left.4^{\circ} \mathrm{C}\right)$ and the supernatants were filtered through a syringe filter $(0.2-\mathrm{mi}-$ cron pore size; Whatman, USA) before the high performance liquid chromatography (HPLC) analysis. The HPLC analysis was performed on a Hypersil BDS C18 reversed-phase column $(250 \times 4.6 \mathrm{~mm}, 5 \mu \mathrm{m})$ under isocratic conditions, with electrochemical detection. The mobile phase consisted of a $75 \mathrm{mM}$ phosphate buffer containing $2 \mathrm{mM}$ citrate acid, $0.1 \mathrm{mM}$ octanesulfonic acid, and 15\% (v/v) acetonitrile ( $\mathrm{pH}$ 4.6). Electrochemical detection was achieved by setting a glassy carbon working electrode at $+780 \mathrm{mV}$. The final amount of monoamines in tissue sample was expressed as $\mathrm{pg} / \mathrm{mg}$ of tissue, using an external calibration curve.

PSS rats showed significant $(p<0.05$, two-tailed Student's $t$-test) increase in time spent in closed arms and decrease in time spent in open arms during the EPM, which results in a higher AI (Table 1). The relatively small size of the PSS group did not allow statistical distinguishing between PSSresistant and vulnerable animals as in our previous study (Tseilikman et al. 2017); however, all but one PSS animals showed the AI $>8$. An exposure to the PSS increased thalamic 5 -HT $(259.33 \pm 17.11 \mathrm{pg} / \mathrm{mg}$ of tissue versus $199.29 \pm$ $12.62 \mathrm{pg} / \mathrm{mg}$ of tissue in controls, $p<0.05$, two-tailed Student's $t$-test, Fig. 1A) and decreased hypothalamic dopamine concentrations $(321.67 \pm 49.22 \mathrm{pg} / \mathrm{mg}$ of tissue versus 472.67 $\pm 25.3333 \mathrm{pg} / \mathrm{mg}$ of tissue in controls, $p<0.05$, two-tailed Student's $t$-test, Fig. 2C); norepinephrine levels were not different between the groups (Fig. $1 \mathrm{~B}$ and $2 \mathrm{~B}$ ).

The decrease in animals AI after chronic PSS, observed two weeks after the last exposure to the stressor, is similar to this reported in our previous studies (Lazuko et al. 2018; Manukhina et al. 2018).

Table 1. Effect of chronic predator scent stress (PSS) on the rats' behavior using the elevated plus maze (EPM) test

\begin{tabular}{llllccc}
\hline Group & $n$ & $\mathrm{~N}($ Open) & $\mathrm{N}$ (Closed) & $\mathrm{T}$ (Open) & $\mathrm{T}$ (Closed) & AI \\
\hline Control & 7 & $7.43 \pm 1.19$ & $3.71 \pm 0.81$ & $70.00 \pm 11.13$ & $530.00 \pm 11.13$ & $0.77 \pm 0.02$ \\
PSS & 9 & $7.44 \pm 0.73$ & $2.33 \pm 0.29$ & $37.78 \pm 7.03^{*}$ & $562.22 \pm 7.03^{*}$ & $0.85 \pm 0.02^{*}$ \\
\hline
\end{tabular}

$n$, number of animals; $\mathrm{N}$ (Open), number of entrances open arms; $\mathrm{N}$ (Closed), number of entrances to closed arms; $\mathrm{T}$ (Open), time spent in open arms; T (Closed), time spent in closed arms; AI, anxiety index; ${ }^{*} p<0.05 v$ s. control, two-tailed Student's $t$-test. 
A

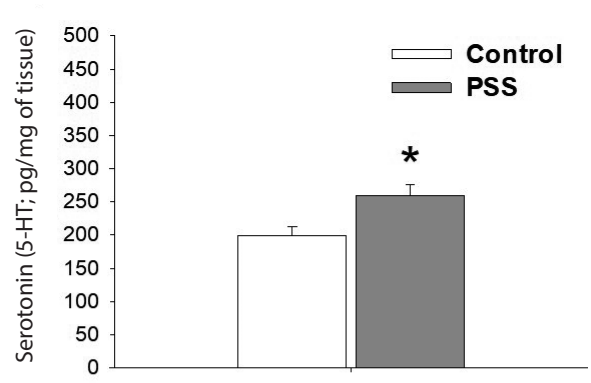

B

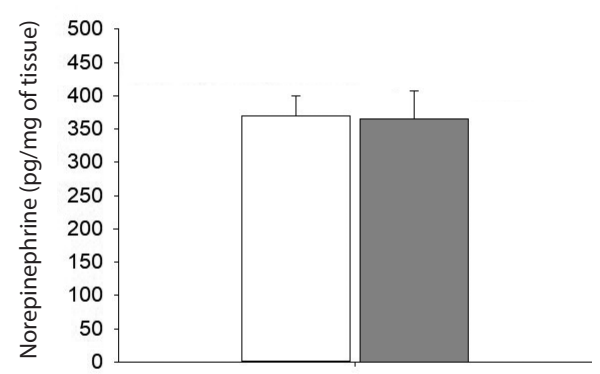

C

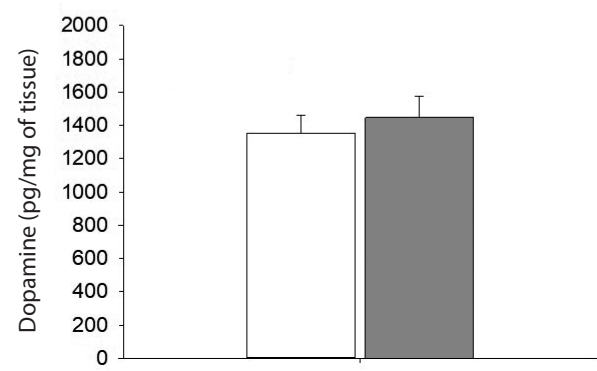

Figure 1. Effect of chronic predator scent stress (PSS) on serotonin (5-HT, A), norepinephrine (B), and dopamine (C) levels in rat thalamus. ${ }^{\star} p<0.05 v$ s. control, two-tailed Student's $t$-test.

Our funding on the altered 5-HT transmission in the thalamus is consistent with previous studies by other groups. Thus, Nikolaus and colleagues (Nikolaus et al. 2010) reported decreased 5-HT transporter (SERT) density in the mesencephalon of patients with PTSD.

We found that PSS did not affect thalamic or hypothalamic norepinephrine and decreased hypothalamic dopamine levels. However, a previous study by Browne and colleagues (Browne et al. 2014) reported a stress-induced decrease in the hypothalamic catecholamines in mice with low fearsensitized acoustic startle reflex. These differences might be explained by different types of stressors (PSS versus acute swim test) and different animals (rats versus mice).

Previous clinical studies reported that the dopamine agonist bromocriptine lowered adrenocorticotropic hormone $(\mathrm{ACTH})$ concentrations in patients with Cushing's and Nelson's syndromes, and subsequent in vitro studies conformed that dopamine decreased ACTH release from cultured human corticotropic adenoma cells (Engler et al. 1999). It is therefore possible that the decreased corticosterone levels, observed in our previous studies with PSS animals, are caused, at least partially, by abnormal hypothalamic dopamine transmission.

To the authors best knowledge, this study was first to examine the effect of PSS on monoamine transmission in the thalamus and hypothalamus. Based on the results provided in this study, it can be suggested that the alterations in thalamic 5-HT and hypothalamic dopamine might play a role in pathophysiology of PTSD. As a pilot study, it did not distinguish between different thalamic and hypothalamic nuclei, as well as between intracellular and extracellular monoamines. Intracellular and extracellular levels of monoamines within the specific thalamic and hypothalamic nuclei should be evaluated in the future studies, using more

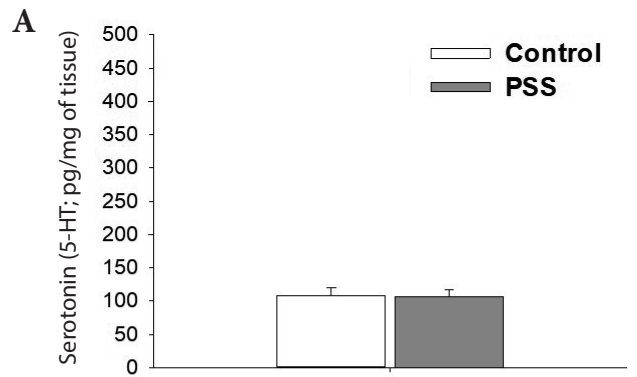

B

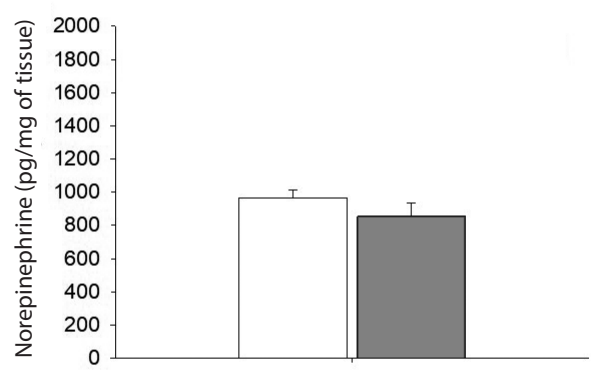

C

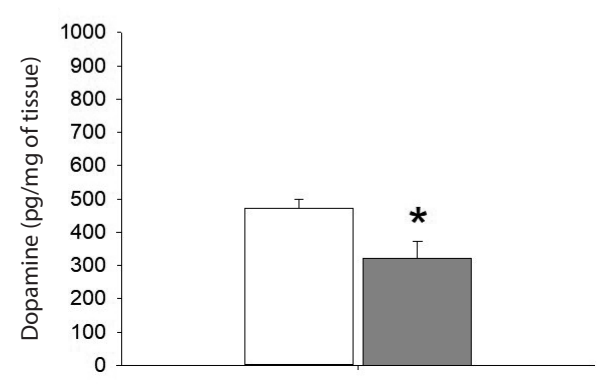

Figure 2. Effect of chronic predator scent stress (PSS) on serotonin (5-HT; A), norepinephrine (B), and dopamine (C) levels in rat hypothalamus; ${ }^{*} p<0.05 v$ s. control, two-tailed Student's $t$-test. 
advanced research methodologies, such as combination of brain imaging and microdialysis.

Acknowledgement. This study was supported by the Russian Science Foundation (grant \#17-15-01318).

\section{References}

American Psychiatric Association, American Psychiatric Association. DSM-5 Task Force (2013): Diagnostic and statistical manual of mental disorders: DSM-5. xliv, p. 947

Boero G, Pisu MG, Biggio F, Muredda L, Carta G, Banni S, Paci E, Follesa P, Concas A, Porcu P, Serra M (2018): Impaired glucocorticoid-mediated HPA axis negative feedback induced by juvenile social isolation in male rats. Neuropharmacology 133, 242-253 https://doi.org/10.1016/j.neuropharm.2018.01.045

Browne CA, Hanke J, Rose C, Walsh I, Foley T, Clarke G, Schwegler H, Cryan JF, Yilmazer-Hanke D (2014): Effect of acute swim stress on plasma corticosterone and brain monoamine levels in bidirectionally selected $\mathrm{DxH}$ recombinant inbred mouse strains differing in fear recall and extinction. Stress 17, 471-483 https://doi.org/10.3109/10253890.2014.954104

Cezario AF, Ribeiro-Barbosa ER, Baldo MV, Canteras NS (2008): Hypothalamic sites responding to predator threats--the role of the dorsal premammillary nucleus in unconditioned and conditioned antipredatory defensive behavior. Eur. J. Neurosci. 28, 1003-1015 https://doi.org/10.1111/j.1460-9568.2008.06392.x

Cooper O, Bonert V, Moser F, Mirocha J, Melmed S (2017): Altered pituitary gland structure and function in posttraumatic stress disorder. J. Endocr. Soc. 1, 577-587 https://doi.org/10.1210/js.2017-00069

Dunkley BT, Wong SM, Jetly R, Wong JK, Taylor MJ (2018): Posttraumatic stress disorder and chronic hyperconnectivity in emotional processing. Neuroimage Clin. 20, 197-204 https://doi.org/10.1016/j.nicl.2018.07.007

Engler D, Redei E, Kola I (1999): The corticotropin-release inhibitory factor hypothesis: a review of the evidence for the existence of inhibitory as well as stimulatory hypophysiotropic regulation of adrenocorticotropin secretion and biosynthesis. Endocr. Rev. 20, 460-500

Feduccia AA, Mithoefer MC (2018): MDMA-assisted psychotherapy for PTSD: Are memory reconsolidation and fear extinction underlying mechanisms? Prog. Neuropsychopharmacol. Biol. Psychiatry 84, 221-228 https://doi.org/10.1016/j.pnpbp.2018.03.003

Hsu DT, Kirouac GJ, Zubieta JK, Bhatnagar S (2014): Contributions of the paraventricular thalamic nucleus in the regulation of stress, motivation, and mood. Front Behav. Neurosci. 8, 73 https://doi.org/10.3389/fnbeh.2014.00073

Lazuko SS, Kuzhel OP, Belyaeva LE, Manukhina EB, Fred Downey H, Tseilikman OB, Komelkova MV, Tseilikman VE (2018): Posttraumatic stress disorder disturbs coronary tone and its regulatory mechanisms. Cell. Mol. Neurobiol. 38, 209-217 https://doi.org/10.1007/s10571-017-0517-X

Manukhina EB, Tseilikman VE, Tseilikman OB, Komelkova MV, Kondashevskaya MV, Goryacheva AV, Lapshin MS, Platkovskii PO, Alliluev AV, Downey HF (2018): Intermittent hypoxia improves behavioral and adrenal gland dysfunction induced by post-traumatic stress disorder in rats. J. Appl. Physiol. 125, 931-937 https://doi.org/10.1152/japplphysiol.01123.2017

Nikolaus S, Antke C, Beu M, Muller HW (2010): Cortical GABA, striatal dopamine and midbrain serotonin as the key players in compulsive and anxiety disorders--results from in vivo imaging studies. Rev. Neurosci. 21, 119-139 https://doi.org/10.1515/REVNEURO.2010.21.2.119

Paxinos G, Watson C (2013): The Rat Brain in Stereotaxic Coordinates (7th edition). Academic Press, Cambridge, MA, USA

Silva BA, Burns AM, Graff J (2018): A cFos activation map of remote fear memory attenuation. Psychopharmacology (Berl) 2018, 1-13 https://doi.org/10.1007/s00213-018-5000-y

Stahl SM, Grady MM, Muntner N (2014): Stahl's Essential Psychopharmacology: Prescriber's Guide. Cambridge University Press, New York, NY, USA

Tseilikman OB, Lapshin MS, Komelkova MV, Kondashevskaya MV, Dremencov EV, Manukhina EB, Downey HF, Lazuko SS, Kuzhel OP, Tseylikman VE, Kozochkin DA (2017): Adrenal insufficiency in rats after prolonged exposure to the predator cue: A new animal model of post-traumatic stress disorder. Psychoneuroendocrinology 83, 83

https://doi.org/10.1016/j.psyneuen.2017.07.460

Received: September 24, 2018

Final version accepted: January 9, 2019

First published online: March 1, 2019 